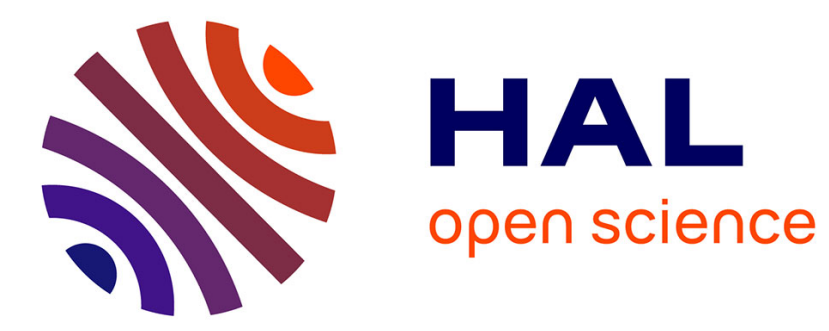

\title{
The behaviour of a floating water bridge under reduced gravity conditions
}

\author{
Elmar C Fuchs, Luewton L F Agostinho, Adam Wexler, R Martijn \\ Wagterveld, Jan Tuinstra, Jakob Woisetschläger
}

\section{- To cite this version:}

Elmar C Fuchs, Luewton L F Agostinho, Adam Wexler, R Martijn Wagterveld, Jan Tuinstra, et al.. The behaviour of a floating water bridge under reduced gravity conditions. Journal of Physics D: Applied Physics, 2011, 44 (2), pp.25501. 10.1088/0022-3727/44/2/025501 . hal-00586987

\section{HAL Id: hal-00586987 https://hal.science/hal-00586987}

Submitted on 19 Apr 2011

HAL is a multi-disciplinary open access archive for the deposit and dissemination of scientific research documents, whether they are published or not. The documents may come from teaching and research institutions in France or abroad, or from public or private research centers.
L'archive ouverte pluridisciplinaire HAL, est destinée au dépôt et à la diffusion de documents scientifiques de niveau recherche, publiés ou non, émanant des établissements d'enseignement et de recherche français ou étrangers, des laboratoires publics ou privés. 


\title{
The behavior of a floating water bridge under reduced gravity conditions
}

\author{
Elmar C. Fuchs ${ }^{1 *}$, Luewton L.F. Agostinho ${ }^{1}$, Adam Wexler ${ }^{1}$, R. Martijn Wagterveld ${ }^{1}$, Jan \\ Tuinstra $^{1}$ and Jakob Woisetschläger ${ }^{2}$ \\ ${ }^{1}$ Wetsus, Center of Excellence for Sustainable Water Technology, Agora 1, 8900 CC Leeuwarden, The Netherlands. \\ 2 Institute for Thermal Turbomachinery and Machine Dynamics, Graz University of Technology, Inffeldgasse 25A, \\ Graz, Austria
}

* Corresponding author. E-mail: elmar.fuchs@ wetsus.nl, phone: +31 (0) 582843162

\begin{abstract}
$\underline{\text { Abstract }}$
When high voltage is applied to pure water filled into two beakers close to each other, a connection forms spontaneously, giving the impression of a floating water bridge [1]-[8]. This phenomenon is of special interest, since it comprises a number of phenomena currently tackled in modern water science. In this work, the behavior of this phenomenon under reduced gravity conditions during a parabolic flight is presented by the means of high speed imaging with fringe projection. An analysis of the behavior is presented and compared to theoretical considerations.
\end{abstract} Supplementary video clips for the sequences shown in figs. 2, 4, $5 \& 6$ as well as $7 \& 8$ are available.

\section{$\underline{\text { Introduction }}$}

In 1893 Sir William Armstrong placed a cotton thread between two wine glasses filled with chemically pure water. After applying a high voltage, a watery connection formed between the two glasses, and after some time, the cotton thread was pulled into one of the glasses, leaving, for a few seconds, a rope of water suspended between the lips of the two glasses [1]. As gimmick from early days of electricity this experiment was handed down through history until the present authors learned about it from W. Uhlig, ETH Zürich [2]. Although easy to reproduce, this watery 
connection between the two beakers, which is further referred to as 'floating water bridge' holds a number of interesting static and dynamic phenomena [3]-[8].

At macroscopic scale several of these phenomena can be explained by modern electrohydrodynamics, analyzing the motion of fluids in electric fields (see, e.g., the Maxwell pressure tensor considerations by Widom et al. [9], or the text book on Electrohydodynamics by Castellanos [10]).

On the molecular scale water can be described by quantum mechanics (e.g. [11],[12]). The gap at mesoscopic scale is bridged by a number of theories including quantum mechanical entanglement and coherent structures in water, theories which are currently discussed (e.g. [13]-[17] for water in general, and [18] specifically for the water bridge). Previous experiments [3] suggested a possible change of the water micro structure inside the water bridge; first neutron scattering experiments [5] showed no difference in the microdensity of a $\mathrm{D}_{2} \mathrm{O}$ bridge compared to the bulk; recent 2D neutron scattering experiments [6] indicated a preferred molecular orientation within a floating heavy water bridge; detailed optical investigations [7] suggested the existence of a mesoscopic bubble network within the water bridge; and a Raman scattering study on vertical water bridges reported on a polarized water structure induced by the electric field [19]. A comprehensive review about water bridge research was published recently [20]. The properties of water at mesoscopic scales have drawn special attention due to their suggested importance to human physiology [21].

In this work, the first reduced gravity experiments with the floating water bridge are presented. The data gathered with high speed imaging and fringe projection are discussed, the overall behavior is described and compared to theoretical considerations.

\section{Experimental}

The experiments were carried out onboard the PH-NLZ Fairchild Metro II Research Aircraft of the NLR (Nationaal Lucht- en Ruimtevaartlaboratorium - The National Aerospace Laboratory of the Netherlands), Hangar 3, Schiphol, on a specially designed set-up (see Fig. 1). All apparatus were mounted on an aluminum alloy plate provided by the NLR using struts and mountings certified for aviation and safe for accelerations up to $9 \mathrm{G}$. The set-up contained a constant current regulated high voltage power supply $(0-20 \mathrm{kV})$ with a $250 \mathrm{k} \Omega / 500 \mathrm{M} \Omega$ voltage divider. Instead of beakers two closed bottles with an additional opening in the sidewall were used. The bottles were 
mounted on a movable stage in order to manually create water bridges of different length. The water bridge was formed between the sidewall openings of the bottles. The bottles were filled with milli-Q water (conductivity $<1 \mu \mathrm{S} / \mathrm{cm}$ ) up to $\sim 2 \mathrm{~mm}$ below these openings. For all experiments, the initial temperature of the water was $\sim 19^{\circ} \mathrm{C}$, which was the onboard air temperature. Due to the short duration of the experiments ( $<1 \mathrm{~min})$, no significant temperature change was to be expected [7]. As electrode material, $2 \times 2 \mathrm{~cm}^{2}$ platinum plates were submerged into the water. One electrode was raised to high potential $(+20 \mathrm{kV})$, the other was grounded to the aircraft's general ground. A $42 \mathrm{nF}$ ceramic capacitor was connected parallel to the electrodes. Background lighting was achieved with an Advanced Illumination BL18120 LED light with a horizontal grid for the fringe projection technique. For the first experiment, the onboard gravity was measured using a gravity meter (compactly shown as "G" component in Fig. 1) consisting of a $1 \mathrm{~kg}$ weight on top of a pressure dependent resistor which was supplied by a $9 \mathrm{~V}$ battery. This resistor was put in series with a $470 \mathrm{k} \Omega$ resistor. A Photron SA-1 high speed camera was synchronized to a Contec AD12-16U(PCI)EV data acquisition board so that images, applied voltage (the voltage drop over the $250 \mathrm{k} \Omega$ resistor) and gravity (the voltage drop over the $470 \mathrm{k} \Omega$ resistor) could be recorded simultaneously. Camera and data acquisition board were controlled via an HP laptop computer using the PVF Photron software. The electricity for the whole set-up was provided by a DC/AC converter which was connected to the aircraft's internal power bus. The bridge's diameter and length were determined by comparison with the (known) dimension of the bottles (and their openings, respectively). Under normal gravity conditions, the diameter was $\sim 2.5 \mathrm{~mm}$ with fluctuations of about $0.5 \mathrm{~mm}$, comparable to previous experiments [3-7].

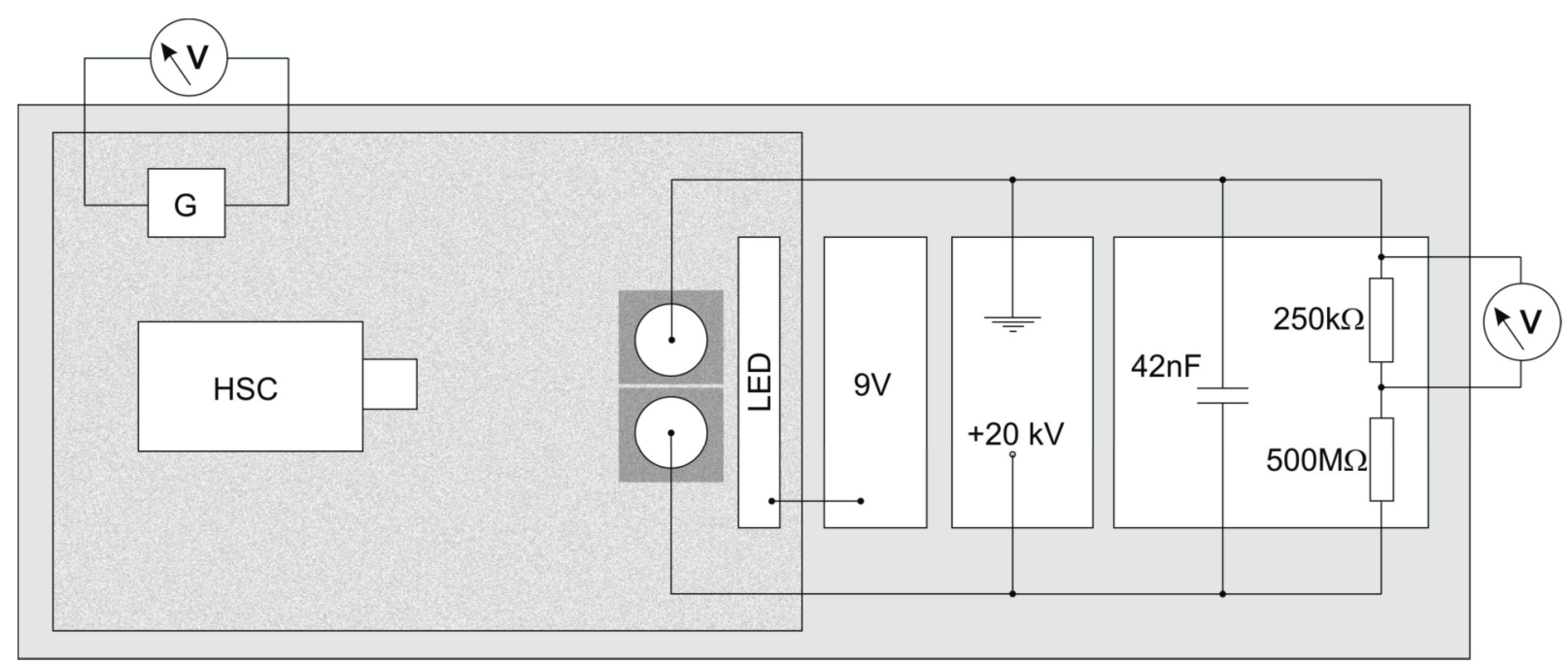


Fig. 1: Sketch of the zero-G water bridge set-up. The circles at center are the bottles filled with water, the grey squares are movable platforms. Abbreviations: HSC...High speed camera; G...gravity meter; LED... LED backlight; $9 \mathrm{~V} \ldots 9 \mathrm{~V}$ power supply for the backlight. The voltmeter symbols show where the signals for the data acquisition board were taken from.

Three different experiments were carried out:

1.) A bridge was created under normal gravity conditions, then a short ( $3 \mathrm{sec})$ parabolic maneuver was aviated. For this experiment, high speed imaging, gravity and the applied voltage were recorded. This experiment ended with the return of gravity.

2.) A bridge was created under normal gravity conditions, then a longer $(\sim 12 \mathrm{sec})$ parabolic maneuver was aviated. For this experiment, high speed images were recorded.

3.) A parabolic maneuver was aviated without a bridge, and the high voltage was applied during reduced gravity conditions. For this experiment, high speed images and applied voltage were recorded. The data acquisition started during the zero-G phase which lasted $\sim 3$ seconds and ended after the return of gravity.

For all experiments, the frame rate was 1000 frames per second with an exposure time of 1/1000 sec. When the data acquisition board was used, one data set per frame was recorded. The right bottle was always grounded (aircraft common ground), and the left bottle raised to high potential.

\section{$\underline{\text { Results }}$}

The behavior of the bridge during experiment one is depicted in Fig. 2; gravity and applied voltage for this experiment are shown in Fig. 3. 

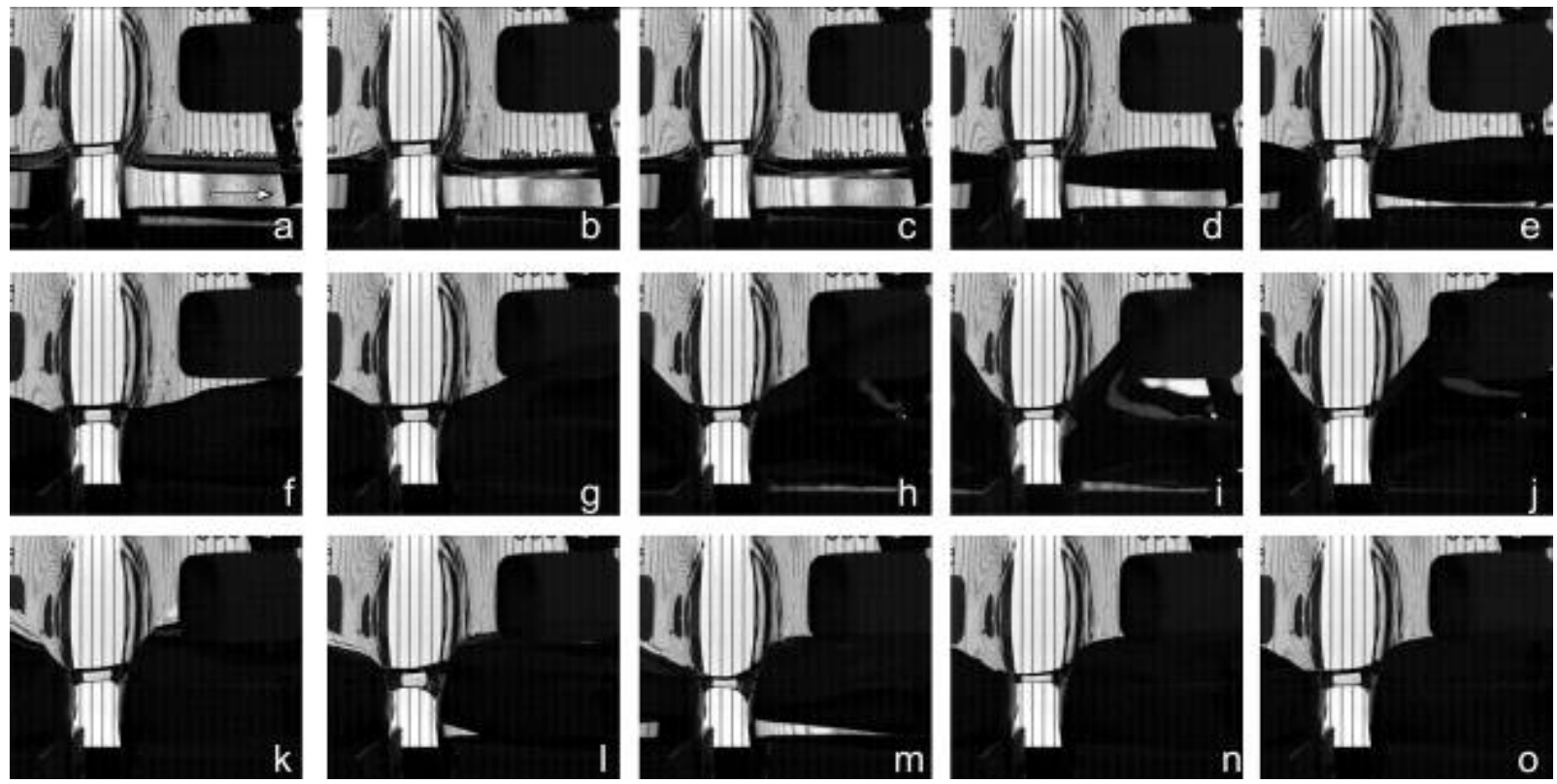

Fig. 2: The floating water bridge under decreasing gravity (a), reduced gravity (b-i), and increasing gravity again (jo). The time between the images is $200 \mathrm{~ms}$. (see also Fig. 3), the white arrow in (a) shows the position of the grounded electrode. 


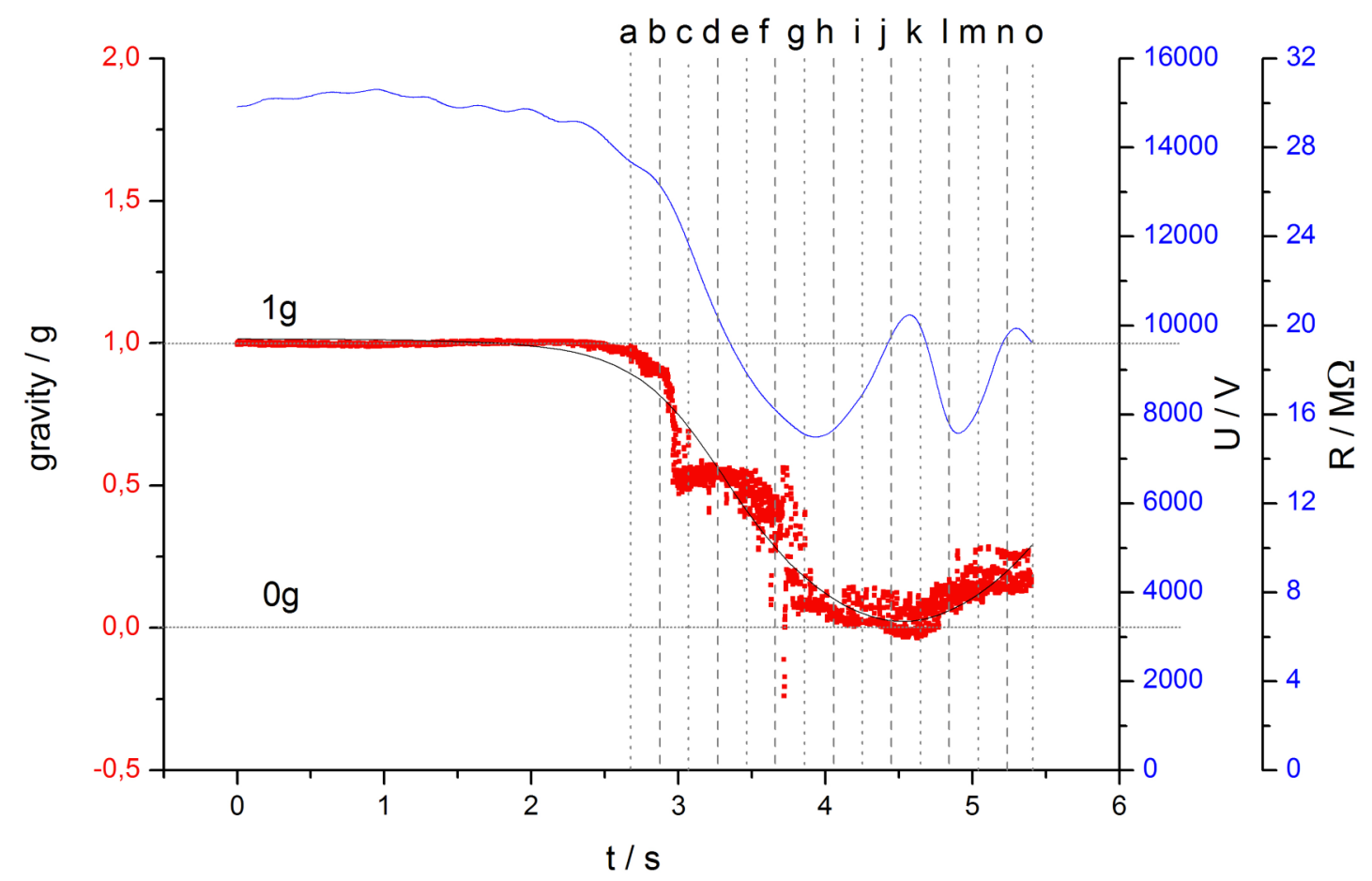

Fig. 3: Gravity and applied high voltage during experiment one. The letters signify the recording time of the images shown in Fig. 2 (highlighted by the vertical lines below each letter), the horizontal lines represent the voltages of the gravity meter for normal gravity $(1 \mathrm{~g})$ and zero gravity $(0 \mathrm{~g})$, respectively.

Typically, in order to get real microgravity conditions $\left(\sim 10^{-6} \mathrm{~g}\right)$ during parabolic flights, the experimental package is isolate from the aircraft thus allowing it to float freely. For the set-up described, this was not possible due to safety reasons. Thus, when attached to the aircraft, fluctuations of a few tens to hundreds of mg are usually observed, which agrees with the gravity meter record in Fig 3. Moreover, the data shows a short hold of the gravity at 0.5 of its normal value at $\sim 2.85 \mathrm{~s}$. Presumably, this is either due to the software problem [22], or the weight in the gravity meter became momentarily stuck due to horizontal acceleration forces - or it was simply a bumpy parabola. However, a malfunction cannot be entirely excluded. Thus an average function was overlaid in Fig.3, and actually both curves are in rough agreement with the behavior of the water in the bottles: It rises from image $\mathbf{a}$ to $\mathbf{j}$ and starts to come down again in image $\mathbf{k}$. Since the gravity meter did not work properly during this experiment, and not reliably at all during the other experiments, the authors plan to replace it with an accelerometer in the future. 
The brief deprivation of gravity established an oscillatory process in the bridge. Its diameter first increased $(\mathbf{a}-\mathbf{f})$ and then decreased $(\mathbf{g}-\mathbf{j})$. After the return of gravity, it increased again $(\mathbf{k}-\mathbf{o})$. This oscillation can also be seen in the applied voltage (blue curve, Fig. 3): as the bridge's diameter increases, its resistance and therefore the applied voltage drops as the current is kept constant by the power supply to $0.5 \mathrm{~mA}$.

The arrangement for experiment two was similar to experiment one. An $8.4 \mathrm{~mm}$ bridge $(\sim 3 \mathrm{~mm}$ diameter) was created under normal gravity, then a longer zero-G maneuver was aviated. This was done in order to test if the bridge length could be increased over the normal maximum length for the voltage applied ( $2 \mathrm{~cm}$ at $20 \mathrm{kV}$, see Refs. [3] and [7]). However, before the experiment could be completed, at a distance of $13.8 \mathrm{~mm}$, the bridge disappeared. This was probably due to the oscillation process which started in this experiment as well, but since the zero $G$ phase lasted longer, instead of increasing its diameter again, the bridge separated entirely. This effect is shown in Fig. 4. First the bridge diameter increases (b-e), and then decreases (f-g) until it ruptures (h).
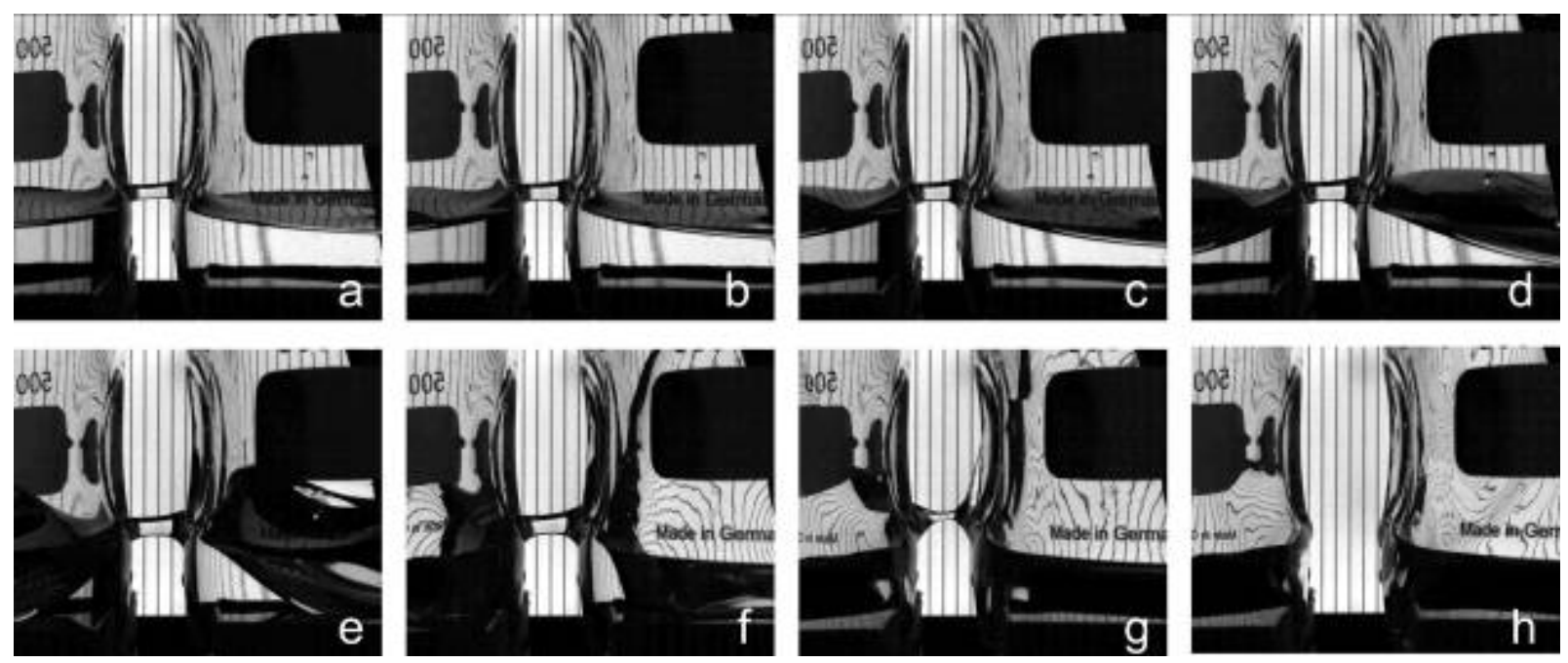

Fig. 4: A bridge is formed under normal gravity conditions (a), then gravity is decreased (b-h). The time between the images is $200 \mathrm{~ms}$.

A detailed observation of the rupture process is given in Fig. 5. Bridge failure under zero G resembles what happens when the high voltage is switched off under normal gravity or when detergents are added [2]. First the diameter is decreased to $\sim 0.2 \mathrm{~mm}$ (a-e). After that, pearl-like sections are formed in the water string (f) until it bursts into a series of droplets (g). Whereas under normal gravity conditions these droplets fall down [2], here they fly along the electric field 
lines in both directions (h), partly bouncing off, with the remnants of the water bridge still clinging to the bottle walls. This effect is shown in detail in Fig. 6.
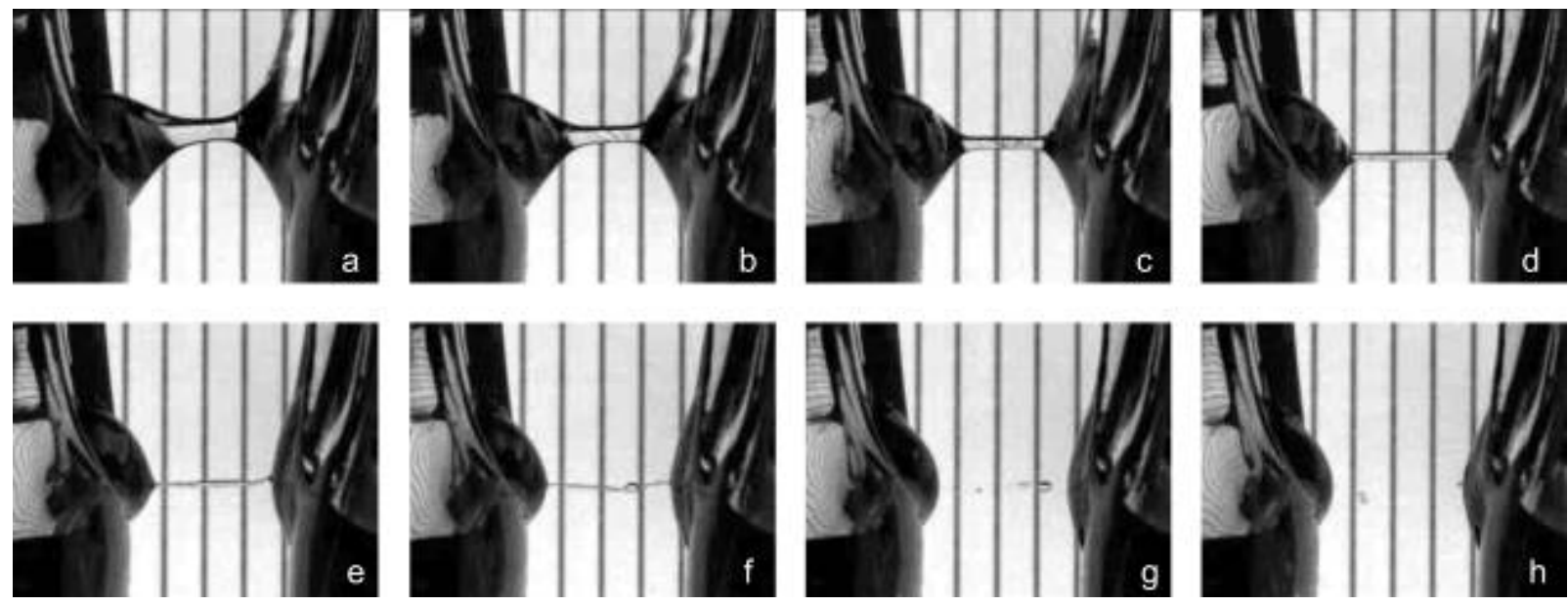

Fig. 5: Break-up of the floating water bridge under zero-G conditions, bottle distance $13.8 \mathrm{~mm}$. The time interval between the images is $200 \mathrm{~ms}(\mathrm{a}-\mathrm{d})$ and $100 \mathrm{~ms}(\mathrm{e}-\mathrm{h})$, respectively.

A logical difference from a breakdown under normal gravity is that the remaining droplets experience the electric force only, thus their movement is horizontal only. This is demonstrated in Fig. 6: The bridge breaks up into four distinct droplets as indicated in image a: one directly in front of the second gridline (1), one between the second and the third grid line (2), one between the third and the fourth grid line (3), and a larger one on the fourth grid line (4). 

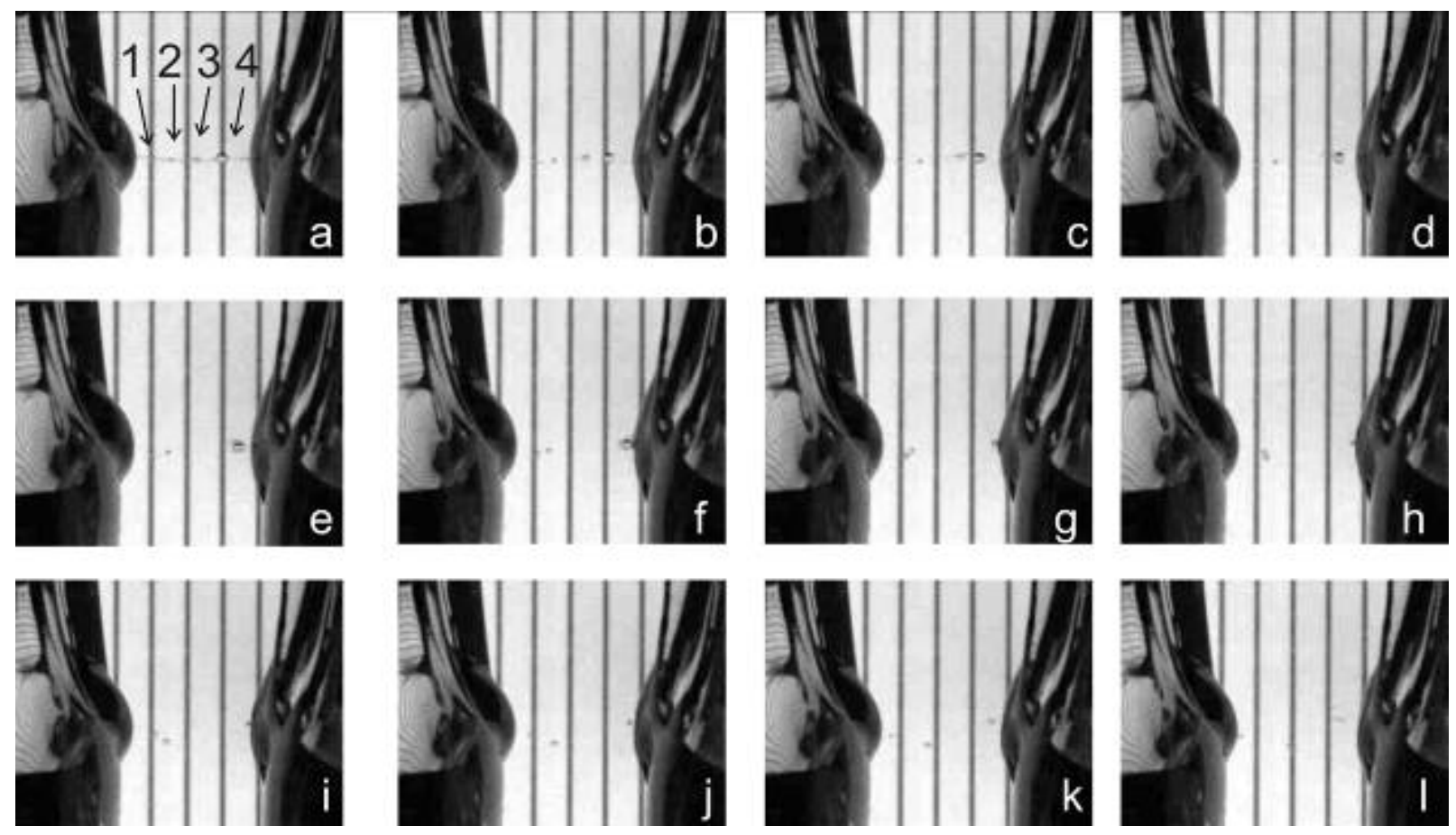

Fig. 6: Droplets bouncing off the water remains on both bottle edges after the breakdown of the floating water bridge under zero-G conditions. The time interval between the images is $1 \mathrm{~ms}$.

Nr. 1 and 2 first stay afloat at their position (a-e), then Nr. 1 begins to move to the right, whereas Nr. 2 moves to the left (f-l). Droplet 3 moves into droplet 4 (d) which then continues moving right. It hits the water surface (f), loses mass ( $\mathbf{g}$-i) and bounces off in the opposite direction $(\mathbf{j}-\mathbf{l})$. This behavior is called "semi-coalescent bouncing" and has been recently reported in electrohydrodynamic atomization experiments with water. A detailed analysis of this effect is given in ref. [23].

In a third experiment, the formation of the bridge under reduced gravity conditions was monitored. The bottles were arranged close together (distance $7.8 \mathrm{~mm}$ ) such that under normal gravity a bridge would undoubtedly form with the application of high voltage. The outcome is shown in Fig. 7. If high voltage is applied under zero $G$, the water bridge does not form (a). During the return of gravity (from $\mathbf{b}$ on), the formation of multiple aqueous connections can be observed. 

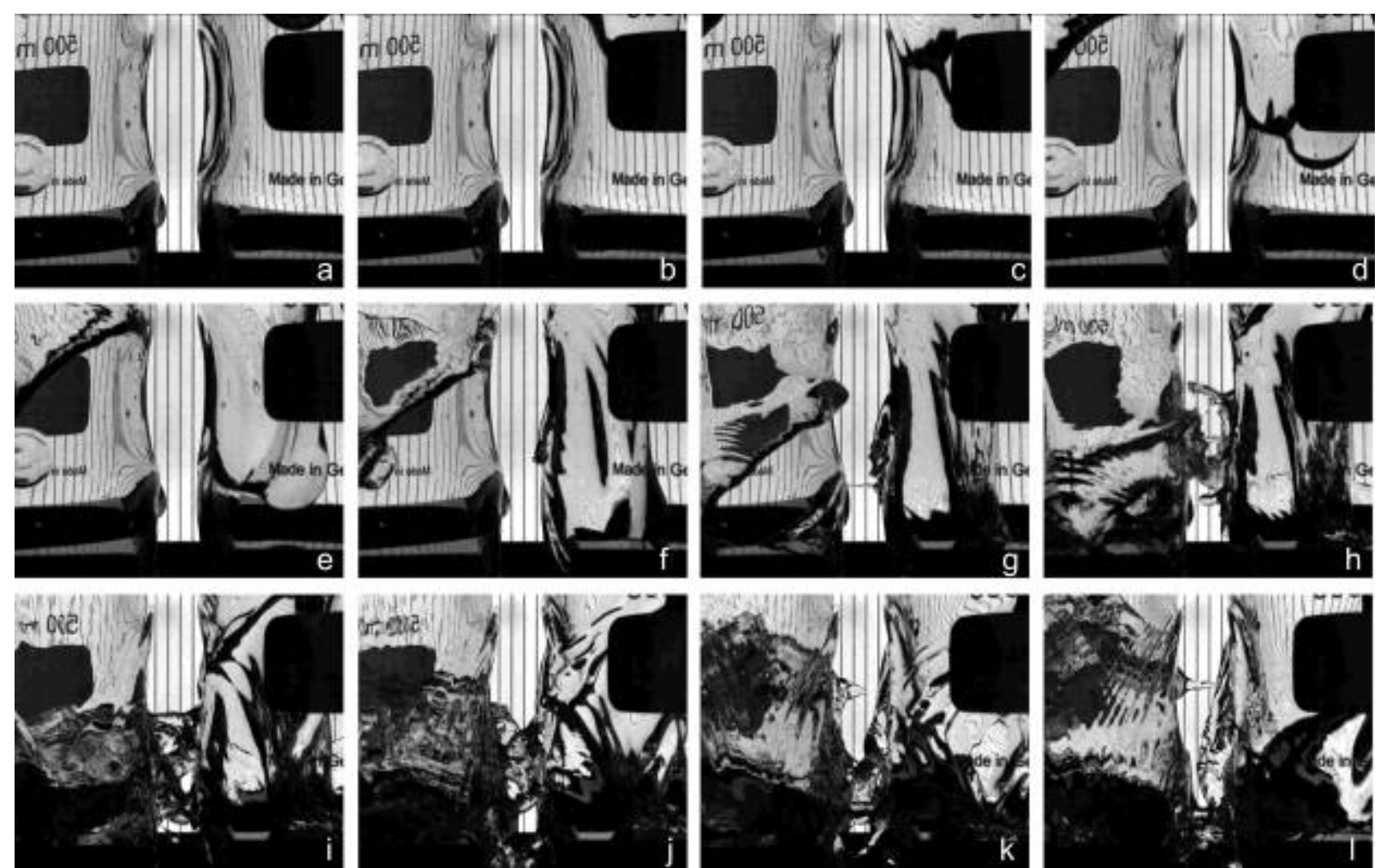

Fig. 7: Bridge formation under returning gravity. No bridge formation was observed in the absence of gravity (a), however the onset of gravitational acceleration (b-1) yielded multiple aqueous connections. The time between the images is $20 \mathrm{~ms}$. 

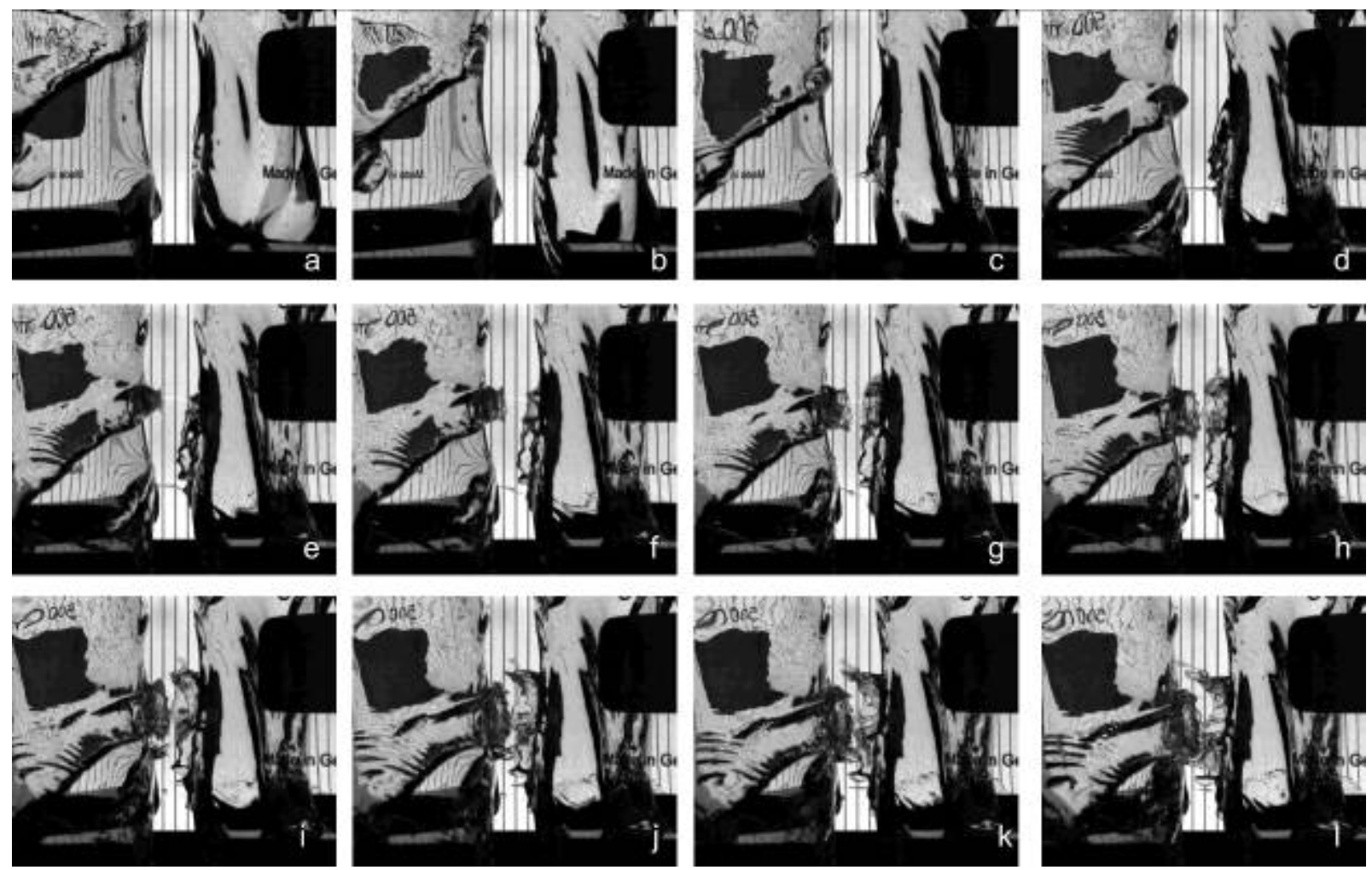

Fig. 8: Detailed analysis of bridge formation under increasing gravity. The time between the images is $10 \mathrm{~ms}$ (a-d) and $2 \mathrm{~ms}$ (e-1), respectively.

The exact moment of bridge formation (between Fig. $7 \mathbf{f}$ and $\mathbf{g}$ )) is analyzed in more detail in Fig. 8. In the right (grounded) beaker, bridge formation starts with water running down the bottle walls (Fig. 8 b-d) which is accompanied by a rising of the water in the left (high voltage) bottle (c-d) connected to the falling water in the right (grounded) bottle. The small bridge visible in (d) is destabilized by the fluid discharge caused by the falling water (e); and the subsequent formation of a much larger aqueous connection (f-l) resulting in multiple bridges (Fig. 7i) which collapse under their own weight while new watery connections are constantly formed above them (Fig. 7j-l).

\section{$\underline{\text { Discussion }}$}

The deprivation of gravity seems to have a profound effect on the floating water bridge: It is severely destabilized and, if exposed to reduced gravity conditions long enough, destroyed. Moreover, reduced gravity inhibits bridge formation which only begins once gravity returns. 
The most obvious reason for that could be that in zero G, there is no contact between the electrodes and the water in the bottles. This possibility, however, is ruled out by observations and considerations: Most important, in experiment one the electrode in the right-hand bottle is visible (see arrow in Fig. 2a): it is almost touching the bottom of the bottle. Since this depth was the same for all experiments, there was always contact between the electrodes and the bottle water. Secondly, due to the hydrophilic electrode surface and the Sumoto effect [24], a separation of the water from the electrodes is not expected. Third, during the last experiment, the bridge formation started with both falling and bottom water (see e.g. Fig. $8 \mathrm{~d}$ and e), meaning that all the water was in contact with the electrode since previous experiments have shown that the bridge is not formed due to the applied field alone but requires an electric current flow [7].

The destabilization of the bridge starts with an increase in diameter which is followed by a decrease which may either lead to heavy oscillations (experiment one) or to the destruction of the bridge (experiment two). The authors plan to repeat these experiments in order to find out if a critical maximum life time under micro-gravity can be determined. From the present experiment, this time is roughly $1.5 \mathrm{~s}$. Idealizing the bridge as a resistor-capacitor element, this time would represent the relaxation time of the $\mathrm{RC}$ circuit. This is slightly longer than the time delay observed during start-up in previous experiments $(0.5-1 \mathrm{~s})$ [7]. Initially, a watery connection or 'capillary bridge' forms between the two beakers when a high voltage is applied; this is well known from electrowetting and is essentially an electrostatic phenomenon [25]. Once established, current begins to flow through the thin watery connection causing a magnetic field along the capillary bridge to rise which focuses the electric field resulting in a thick and stable water bridge. This process occurs within the above mentioned time-scale.

These results raise serious questions about the role of gravity in this phenomenon, since it is not straightforward that gravity is essential for both its formation and its stability. Previous experiments have shown that the water flows in spirals through the outer layer of the bridge [5],[7]. From basic hydrodynamics it is straight forward that the driving force for this rotation can be gravity. It has been suggested that the rotation stabilizes the bridge [5], and it has been observed that the speed of rotation decreases with increasing bridge diameter [7]. Thus an increase in diameter, as it was observed in experiment 1 and 2, is probably accompanied by a decrease in rotational speed. However, since the diameter is decreasing again afterwards, an increase of the rotational speed would be expected. Therefore, the authors plan additional experiments with tracer particles visualizing the rotation of the outer layer. 
The break-up of the bridge is comparable to what happens if detergents are added to a bridge or if the voltage is shut off [3] with the difference that under micro-gravity none of the droplets falls down. Since break-up droplets move in different directions, one can safely assume that they carry different charges, which indicates that there are both positive and negative charges flowing simultaneously through the water bridge or charge separation takes places during break-up. In this experiment, stable water remnants at the bottle openings could be observed in response to the absence of normal gravity, illustrating another novel effect which was recently discovered by Agostinho et al. [23]: One of the droplets looses mass upon contact with the beaker water and is then ejected into the opposite direction. This is called "semi-coalescent bouncing" and involves charge transfer between droplet and "cone" (or water remnant, in this case) as well as recharging of the droplet followed by electrostatic repulsion. The process is described in the framework of electrospraying, thus requiring a conductive connection between the water and the electrode, and can therefore be seen as additional proof that the connection to power was never severed during this experiment.

Next to the changes of the bridge itself, a big effect of all experiments is the motion of the bulk liquid in the bottles. In Fig. 2, the liquid in the beakers remains mostly near the openings, though the interface is tilting due to a residual acceleration into the page. In this case, the bridge, though destabilized in the process, remains connected. In Fig. 4, it appears that the liquid begins moving toward the bridge from both sides, but by frame $\mathbf{g}$ most of the liquid has migrated away from the openings, causing the bridge to break.

The question why the bridge would break in such a way deserves detailed analysis: Without gravity, intermolecular forces (water-container interaction forces and surface tension), which are normally mostly overruled by it, become more prominent: These forces are responsible to provide adhesion between water and the glass surface and cohesion between water molecules. This is why water forms spheres in zero gravity, and why it runs up the glass wall of the bottles in this experiment. However, these forces and gravity are defeated by the electric forces of the water bridge when the high voltage is applied. Thus, a priori, one would expect a much more intense formation process without gravity, since now the electric forces only have to overcome intermolecular forces, thus allowing them to act more effectively. In other words, the water which initially moves toward the bridge (Fig. 4 a-f) is expected to flow along the electric field lines, thereby increasing the bridge's diameter. The experiment shows the opposite: The water runs upwards the beaker walls, around the openings - and starts to form jets only when gravity 
returns, not before (see Fig. 7). Moreover, not only the falling water does so, but a jet of upwards crawling water is formed although most of the water is not near the openings during the whole time. This happens only after the term "upwards" is defined again, as can be seen from Fig. $8 \mathrm{~d}-\mathrm{h}$ in the left beaker. It should be noted that the water level in the beakers is the same throughout the observation period, so the most obvious explanation for the observation - the falling water increasing the level to make contact with the electrodes again and/or creating the upwards moving jets starting the process - must most probably be excluded here as well.

The formation and stability of a floating water bridge is dependent on the careful balance of forces at play within the entire system. The principal forces are gravity, inter-molecular forces and the applied electric field. The reduction of gravity will affect a subset of these forces most notably the wetting or adhesive force. The wetting force is stronger than gravitational acceleration in water as evidenced by capillary rise. Under reduced gravity adhesion increases its contribution to the behavior of the whole system. The water is no longer restrained by gravity and climbs up the walls of the bottles. This increase in surface area raises the amount of work done on the system by surface tension. The electric field is also performing work in order to maintain a bridge. Once the contribution from the surface energy work function exceeds that of the electric field work function the formation of a floating water bridge is thermodynamically prohibited. Thus, in the absence of gravity if the bridge is in operation it ruptures, if no bridge exists it cannot form. With the onset of gravitational acceleration the water is pulled from the glass surface by an increase in the weight of the water column. This permits the weaker electric field to once again act on the water, initiating electrospray phenomena which ultimately lead to the formation of the bridge. Additionally, the disruption of a floating water bridge by the introduction of surfactants indicates that bridge formation can only take place when the surface energy of the system is within certain limits.

While the above discussion of the effect uses a conventional approach it must be mentioned that the electric field induces a polarization and self-arranging of water molecules in the bridge as observed by neutron scattering experiments [5],[6].

\section{$\underline{\text { Conclusions }}$}


Water bridge experiments performed under micro gravity helped to identify and confirm relevant time scales in the formation and destruction of this phenomenon. Previous experiments showed that under the influence of a sufficiently high voltage a Taylor cone forms on both sides from which the water is electrosprayed. This electrospray provides an aqueous connection between the water in the two beakers and a current starts to run through this watery connection causing a significant mass flow, mainly from the anode to cathode beaker [3],[4],[7]. Under stable conditions water flows in both directions [7]. What is new is that under micro gravity this flow is halted, approximately at the same time-scale needed for bridge formation, i.e. the time from the first water connection (capillary bridge) to the thick and stable bridge. This indicates that a careful balance between gravity, adhesion, cohesion, and the applied electric field is necessary for the formation of a stable water bridge. But since the force measured between the beakers in previous experiments [4],[7] is larger than the electric drag force for water with a conductivity < $1 \mu \mathrm{S} / \mathrm{cm}$, additional stability might be added to the bridge by molecular orientation [6] or vibrational coupling [18],[26]. The interplay of these forces could be changed in reduced gravity conditions, thus destabilizing the bridge.

Obviously, more low gravity experiments with the floating water bridge are called for. We aim to improve the set-up in order to better control the position of the bulk liquid, using e.g. hydrophobic coating in the bottles. In order to avoid excessive g-jitter, we furthermore plan to do future experiments in a much lower gravity environment, e.g. by constructing a safe free-floating set-up inside of the plane. With these experiments, we intend to verify the hypotheses suggested in this work.

\section{Special acknowledgements}

The authors would like to thank the Gerrit Oudakker of Wetsus for his indestructible optimistic efforts which paved the way for this experiment. Consequently, we would like to thank the NLR for making this experiment possible, especially the pilots Ger Nielen and Wim Bonnee for fantastically aviating the parabolic manoeuvres. In addition, we would like to thank Prof. Cees Buisman of Wetsus for financial support.

Acknowledgements 
With great pleasure, the authors wish to thank Profs. Marie-Claire Bellissent-Funel (Laboratoire Léon Brillouin, Saclay), Eshel Ben-Jacob (Tel Aviv University), Cees Buisman (Wetsus - Centre of Excellence for Sustainable Water Technology), Karl Gatterer (Graz University of Technology), Emilio Del Giudice (Universitá di Milano), Franz Heitmeir (Graz University of Technology), Jan C.M. Marijnissen (Delft University of Technology), Laurence Noirez (Laboratoire Léon Brillouin, CEA-CNRS/IRAMIS, CEA-Saclay), Gerald H. Pollack (University of Washington), José Teixeira (Laboratoire Léon Brillouin, CEA-CNRS/IRAMIS, CEA/Saclay), Giuseppe Vitiello (Universitá degli studi di Salerno), as well as Ingo Leusbrock and Astrid H. Paulitsch (Wetsus, Centre of Excellence for Sustainable Water Technology) for the ongoing discussion on the water bridge phenomenon (in alphabetic order).

\section{$\underline{\text { References }}$}

[1] W.G. Armstrong, Electrical phenomena The Newcastle Literary and Philosophical Society, The Electrical Engineer (1893) 10 February 1893, pp 154-145

[2] W. Uhlig, Personal communication, Laboratory of Inorganic Chemistry, ETH Hönggerberg HCI, CH-8093 Zürich (2005)

[3] E.C. Fuchs, J. Woisetschläger, K. Gatterer, E. Maier, R. Pecnik, G. Holler and H. Eisenkölbl, J. Phys. D: Appl. Phys. 40, 6112-6114 (2007)

[4] E.C. Fuchs, K. Gatterer, G. Holler and J. Woisetschläger, J. Phys. D: Appl. Phys. 41, 1855027 (2008)

[5] E.C. Fuchs, B. Bitschnau, J. Woisetschläger, E. Maier, B. Beuneu, J. Teixeira, J. Phys. D: Appl. Phys. 42, 065502 (4pp) (2009)

[6] E.C. Fuchs, P. Baroni, B. Bitschnau, L. Noirez, J. Phys. D: Appl. Phys. 43, (2010) 105502 (5pp)

[7] J. Woisetschläger, K. Gatterer, E.C. Fuchs, Exp. Fluids 48, 121-131 (2010)

[8] H. Nishiumi, F. Honda, Res. Let. Phys. Chem. 2009, art. ID 371650 (3pp) (2009)

[9] A. Widom, J. Swain, J. Silverberg, S. Sivasubramanian, Y.N. Srivastava, Phys. Rev. E 80, 016301 (7pp) (2009)

[10] A. Castellanos, Electrohydrodynamics, International Centre for Mechanical Sciences, CISM Courses and Lectures No.380, Springer, Wien, New York, Ed. (1998), ISBN 3-211-83137-1 
[11] J. Mrázek, J. V. Burda, J. Chem. Phys. 125, 194518 (2006)

[12] W.L. Jorgensen, J. Tirado-Rives, PNAS Proc Natl Acad Sci. 102, 6685-6670 (2005)

[13] E. Del Giudice, Journal of Physics: Conf. Ser. 67, 012006 (2006)

[14] T. Head-Gordon, M.E. Johnson, PNAS Proc Natl Acad Sci 21, 7973-7977 (2006)

[15] H.E. Stanley, S.V. Buldyrev, G. Franzese, N. Giovambattista, F.W. Starr, Phil. Trans. R. Soc. A 363, 509-523 (2005)

[16] C.A. Chatzidimitriou-Dreismann, T.A. Redah, R.M.F. Streffer, J. Mayers, Phys. Rev. Lett. 79, 2839-2842 (1997)

[17] R. Arani, I. Bono, E. Del Giudice, G. Preparata, International Journal of Modern Physics B 9, 1813-1841 (1995)

[18] E. Del Giudice, E.C. Fuchs, G. Vitiello, Water 2, 69-82 (2010) (ISSN 2155-8434)

[19] R. C. Ponterio, M. Pochylski, F. Aliotta, C. Vasi, M. E. Fontanella, F. Saija, J. Phys. D: Appl. Phys. 43 (2010) 175405 (8pp)

[20] E.C. Fuchs, Water 2, doi: 10.3390/w20x000x (ISSN 2073-4441) in press

[21] G.H. Pollack, Cells, gels and the engine of life, Ebener \& Sons (2001) Seattle WA, ISBN 09626895-2-1

[22] T. Nicholls, Photron Ldt. Japan, private communication (2010)

[23] L.L.F. Agostinho, E.C. Fuchs, C. U. Yurteri, J. C. M. Marijnissen, in preparation (2010)

[24] D. Daba, J. Phys. A Gen. Phys. 5 (1972) 318-326

[25] Mugele and Baret, Electrowetting: from basics to application, J. Phys.: Condens. Matter 17 (2005) R705-R774

[26] M. Yang, J. L. Skinner, Phys. Chem. Chem. Phys. 12, 982-991 (2010) 